\title{
Flame Spread Analysis using a Variable B-Number
}

\author{
ALI S. RANGWALA \\ Assistant Professor \\ Department of Fire Protection Engineering - Worcester Polytechnic Institute, \\ 100 Institute Road, Worcester, MA 01609 \\ Email- rangwala@wpi.edu, Tel - (508) 831-6409, Fax - (508) 831-5862
}

\begin{abstract}
Flame spread over solid materials is commonly described in the literature by a two-dimensional reactive boundary layer solution first formulated by Emmons (1956). In the recent past, experimental measurements associated with material flammability testing (e.g. NASA-STD-6001) are compared with the Emmons solution, as modified by Pagni and Shih (1979), and found in disagreement. In the classical solution, the B-number (Spalding mass transfer number) appears as one of the boundary conditions, and has been traditionally assumed a constant for mathematical simplicity. However, experimental results show that the B-number is not a constant, but varies with time and space. A simple modification to the standard measurement procedure is described, which allows calculation of the B-number from the flame stand-off distance. Measurements of flame standoff distance are performed to determine the B-number as a function of time. The classical combustion problem is revisited to model flame spread over a combustible surface. An experimentally-obtained B-number is used to model flame propagation, showing good agreement with current and previous experimental data obtained from the literature. Implications to microgravity flame spread are discussed.
\end{abstract}

KEYWORDS: standoff distance, flame spread, B-number

\section{NOMENCLATURE LISTING}

\begin{tabular}{|c|c|c|c|}
\hline $\begin{array}{l}A_{\text {free }} \\
A_{\text {forced }}\end{array}$ & $\begin{array}{l}\text { Integral constants based on natural forced } \\
\text { convection }\end{array}$ & $\dot{M}_{f, e}^{\prime}$ & Excess- fuel fraction $(\mathrm{g} / \mathrm{cm} \mathrm{s})$ \\
\hline$B$ & Mass-transfer number, Spalding B-number & $q$ & Losses at the fuel surface $(\mathrm{J} / \mathrm{g})$ \\
\hline$B_{A}$ & Adiabatic B-number & $\dot{q}_{s, c}^{\prime \prime}$ & In-depth conduction $\left(\mathrm{J} / \mathrm{gm}^{2} \mathrm{~s}\right)$ \\
\hline$B_{C}$ & Critical B-number & $\dot{q}_{s, r}^{\prime \prime}$ & Surface re-radiation $\left(\mathrm{J} / \mathrm{gm}^{2} \mathrm{~s}\right)$ \\
\hline$B_{R}$ & $\begin{array}{l}\text { Maximum B-number for laminar flame } \\
\text { propagation }\end{array}$ & $\dot{q}_{f, r}^{\prime \prime}$ & $\begin{array}{l}\text { Radiative feedback from the flame } \\
\left(\mathrm{J} / \mathrm{gm}^{2} \mathrm{~s}\right)\end{array}$ \\
\hline C & A constant, Equation 3 & $v_{s}$ & $\begin{array}{l}\text { Oxygen-fuel mass stoichiometric } \\
\text { ratio }\end{array}$ \\
\hline$C_{p}$ & Specific heat at constant presure $(\mathrm{J} / \mathrm{gK})$ & $\mathrm{T}$ & Time (s) \\
\hline$F_{e}$ & Excess fuel fraction & $\mathrm{T}$ & Temperature $(K)$ \\
\hline$g$ & Acceleration due to gravity $\left(\mathrm{cm} / \mathrm{s}^{2}\right)$ & $T_{p}$ & $\begin{array}{l}\text { Pyrolysis temperature of the solid } \\
\text { fuel }(K)\end{array}$ \\
\hline$h$ & Enthalpy & $\mathrm{U}_{\infty}$ & $\begin{array}{l}\text { Free stream velocity (forced } \\
\text { convection, } \mu \text { g data) }(\mathrm{mm} / \mathrm{s})\end{array}$ \\
\hline$h_{\text {vap }}$ & $\begin{array}{l}\int_{T_{\infty}} C_{p} d T \text { (Energy needed to raise temperature of } \\
\text { fuel from ambient to its vaporization } \\
\text { temperature }(\mathrm{J} / \mathrm{g})\end{array}$ & $x_{p}$ & $\begin{array}{l}\text { Pyrolysis length (length of fuel } \\
\text { that's gasifying at a given instant of } \\
\text { time) }(\mathrm{cm})\end{array}$ \\
\hline$L$ & Latent heat of vaporization $(\mathrm{J} / \mathrm{g})$ & $x_{f}$ & Flame length $(\mathrm{cm})$ \\
\hline$\Delta H_{C}$ & Heat of combustion $(\mathrm{J} / \mathrm{g})$ & $Y_{i}$ & Mass fraction \\
\hline$\Delta H_{P}$ & Heat of gasification $\left(L+C_{p}\left(T_{p}-T_{\infty}\right)\right)(\mathrm{J} / g)$ & $y_{f}$ & Flame standoff distance $(\mathrm{cm})$ \\
\hline$\dot{M}_{f}^{\prime}$ & Rate of fuel vaporization $(\mathrm{g} / \mathrm{cms})$ & & \\
\hline
\end{tabular}




\section{Greek symbols}

$\mathrm{H} \quad$ Similarity variable

$v \quad$ Kinematic viscosity $\left(\mathrm{cm}^{2} / \mathrm{s}\right)$

P Density $\left(\mathrm{g} / \mathrm{cm}^{3}\right)$

$\tau \quad \frac{h_{\text {vap }}}{L}$

$\chi \quad$ Fraction of flame radiation that is lost to the environment
Subscripts

S Solid

$\infty \quad$ Ambient

f Flame

F Fuel

W Wall

\section{INTRODUCTION}

The prediction of microgravity flame spread based on a combination of theory and earth-gravity measurements is crucial to the design of long-term space vehicles, extraplanetary habitats, and for the prediction of fire risk in these environments. The necessary flammability requirements for all materials to be used in space vehicles (NASA specifications) are given by the: "Flammability, Odor, Offgassing, and Compatibility Requirements and Test Procedures for Materials in Environments that Support Combustion" document [1]. This document specifies two tests that need to be performed before a material is qualified to be used in a space vehicle, the "Upward Flame Propagation Test" (Test 1) and the "Heat and Visible Smoke Release Rates Test" (Test 2). These two tests are expected to properly assess the flammability of a material in micro-gravity conditions. These two test methods attempt to provide a worst-case spread scenario (Test 1) and a measure of the heat release (Test 2), and consequently, the "damage potential" of a fire. A detailed description of these test methods is provided in reference [1] and an extensive list of the materials that have been tested is provided in the "Materials Selection List for Space Hardware Systems" [2]. The Upward Flame Propagation test is designed with the objective of determining whether, when exposed to a standard ignition source, a material would self-extinguish and not transfer burning debris which could ignite adjacent materials (NASA-NHB 8060.1, 1981). The test is conducted at a worst-case thickness and under a worst-case environment. Under this assumption upward flame spread is considered the worst-case scenario, and material thickness (dependent on the combustible studied) and mounting conditions are chosen to mimic these criteria. The environment oxygen concentration is chosen to meet concentrations found in a spacecraft. No forced-flow is considered and the oxygen entrainment towards the flame is driven by buoyancy alone (NASA-NHB 8060.1 (1981)).

The material to be tested is mounted vertically on a sample holder as shown in Fig. 1. The material is ignited at the base (the igniter design is discussed in NASA-NHB 8060.1 (1981), and Friedman [3]), and the flame propagation is recorded on a video camera. The passing criteria for this test is for the flame to self extinguish before the propagation has reached 6 inches $(\sim 15 \mathrm{~cm})$, with self-extinction defined as "burned less than 6 inches $(\sim 15 \mathrm{~cm})$ when exposed to an ignition source." Figure 1 shows a photograph of a material that has failed this test because the flame length has exceeded $15 \mathrm{~cm}$. The time of burn propagation is recorded. However, there is no specific maximum test duration time that is mentioned in the NASA test protocol (NHB8060.1).
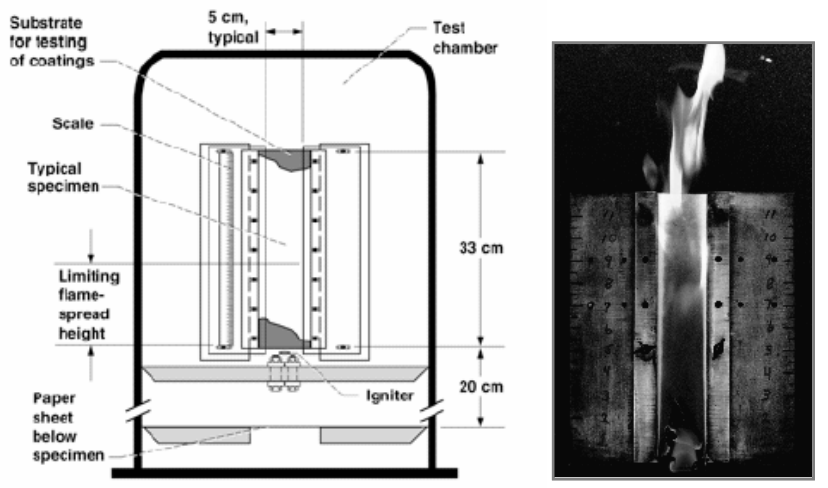

Fig. 1: Upward flammability test [3]. Picture on the right shows a sample failing the test [4], by flame spread criteria (flame length exceeds $15 \mathrm{~cm}$ ). 
The relevance of Test 1 to material flammability for microgravity applications is explored by Ohlemiller and Villa (1991) [5]. Ohlemiller and Villa conducted a series of tests following the protocol of Test 1 with modifications including pre-heating by external radiation and compare the results with tests conducted with the cone calorimeter and the L.I.F.T. (ASTM-E-1321). They find that Test 1 does not address key issues of material flammability. Additional criticism towards the use of the current methodology is found in microgravity combustion literature (Torero et al., 1997 [6], Coutin et al., Rangwala et al., and Ruff et al. [7-10]). Studies have questioned whether the concept of co-current spread is indeed the worst case scenario (Grayson et al., 1994 [11], Ferkul et al. [12] 1993, and Kashiwagi et al. 1997 [13]) and reverse flammability rankings (a material flammability ranking based on downward/opposed flow flame spread) are presented (T'ien[14]).

The importance of understanding flammability returns attention to Test 1 and its applicability as a flammability test. Test 1 uses an on/off screening criterion and there is no quantifiable data that connects material flammability to this test. This study develops a methodology of extracting a material flammabilityrelated nondimensional number (B-number) from a test apparatus similar to Test 1 , allowing a more meaningful data-recovery from the test apparatus in comparison to the current video recordings. The Bnumber extracted from this test can then be used in a flame spread model to estimate flame propagation. The B-number can also be used to rank materials based on their propensity to sustain a co-current flame spread.

Pioneering work on modeling flame spread includes the work of Emmons [15] and Lees [16] in 1956 where a solution for the burning rate of a diffusion flame established over a liquid fuel and subject to a forced flow parallel to the surface is obtained. Emmons shows that the local burning rate or mass loss rate varies inversely with the square root of the distance from the leading edge and varies directly with the square root of the air velocity. Due to the simplicity of the closed-form equation, Emmons' classical solution is used widely and provides a starting point for flame propagation studies done later. Emmons uses a mass-transfer number, or "B-number," a property of the pyrolyzing material to determine the boundary condition at the fuel surface. The B-number (also called Spalding mass transfer number) was first introduced by Spalding [17] in 1950 to characterize liquid fuel droplet burning and physically relates the heat release related to combustion (the numerator) to the losses associated with combustion (the denominator). The B-number is defined by Emmons as:

$$
B=\frac{(1-\chi)\left(\Delta H_{C} Y_{O_{2}, \infty}\right) / v_{s}-C_{p, \infty}\left(T_{p}-T_{\infty}\right)}{\Delta H_{P}+Q},
$$

where $\chi$ corresponds to the fraction of the total energy released by the flame that is radiated to the environment (a function of flame emissivity) and the term $Q$ represents the normalized non-convective heat transfer at the surface. During the early stages, the flame is bright blue in color. With the progress of time it gets brighter as the visible flame radiation increases. It has been shown (for PMMA) that $\chi$ increases with velocity and oxygen concentration using microgravity data by Vietoris et al. [18]. The flame temperature $T_{f}$ is a function of oxygen concentration and $\chi$ is a function of $T_{f}$. Values of $\chi$ for PMMA have been reported in the literature to range from 0.17 to 0.35 , depending on flow geometry. Surface re-radiation and radiative feedback (Fig. 1) to the surface are incorporated through $Q$.

$Q=\frac{\dot{q}_{s, c}^{\prime \prime}+\dot{q}_{s, r}^{\prime \prime}-\dot{q}_{f, r}^{\prime \prime}}{\dot{m}_{F}^{\prime \prime}}$

where $\dot{q}_{s, c}^{\prime \prime}$ represents in-depth conduction, $\dot{q}_{s, r}^{\prime \prime}$ represents surface re-radiation and $\dot{q}_{f, r}^{\prime \prime}$ represents the radiative feedback from the flame. A large B-number implies a highly exothermic fuel relative to the heat required for gasification. The thermodynamic/thermochemical part of the flame spread problem is therefore implicit in the B-number, making the B-number a useful tool to rank material flammability. For example, the adiabatic B-number where $Q$ and $\chi$ are neglected for PMMA is 1.78 [19] and represents the maximum value. Under most conditions, the measured $\mathrm{B}$-number for PMMA is lower than $\mathrm{B}_{\mathrm{A}}$ due the influence of the loss terms $\chi$ and $Q$. However, knowledge of $\mathrm{B}_{\mathrm{A}}$ is valuable from a fire-risk perspective because it represents a worst case flammability behavior in a fire scenario. This has been discussed in detail by Torero et al. [20]. In addition, since there is no loss term $(Q)$ associated with $\mathrm{B}_{\mathrm{A}}$, it can be estimated simply from 
the heat of combustion, ignition temperature, and latent heat of vaporization of the fuel. A more realistic mass transfer number, will have $\chi$ and $Q$, in its formulation and is useful in predicting the flammability of a material in a realistic fire scenario. Previous experimental calculations of the B-number in the literature $[19,21-24]$ have always assumed the loss term $Q$ in the denominator as a constant, resulting in a B-number that does not change with time (Table 1). Kanury [21] measured the radiation losses, and accounted for them in the B-number, when burning solid pool fires under various oxygen concentrations. But since the flame lengths do not change with time (for pool fires with fixed diameters), the loss terms remain constant, and the B-number calculated is a constant. A similar study by Holve and Sawyer [22] where the B-number is measured by burning solid fuels in a counter flow burner configuration also results in a constant Bnumber. Orloff et al. [23] measured the radiative losses of turbulent flames and include this effect in their calculation of the B-number. It is seen from Table 1 that depending on $Q$ and $\chi$ measurements by different researchers, the B-number varies between 1.3 to 1.8 for PMMA. However, using a B-number in this range leads to an over prediction of theory when compared with experimental data [24].

Table 1: B-number values listed in literature (PMMA).

\begin{tabular}{|c|c|}
\hline Reference & B-number estimate \\
\hline Pagni and Shih [25] & 1.5 \\
\hline $\begin{array}{c}\text { Annamalai and } \\
\text { Sibulkin [19] }\end{array}$ & 1.78 \\
\hline Pello [24] & 1.71 \\
\hline Kanury [21] & 1.32 \\
\hline Holve and Sawyer [22] & 1.5 \\
\hline
\end{tabular}

Owing to this discrepancy between classical theory and experimental results, most of the flame spread research in the 1980s and 1990s were concentrated on developing empirical correlations to model flame spread results. These correlations are based on test data like the Radiant Panel Rate of Flame Spread Test [26]. Other experimental correlations are developed from test data by Saito et al. [27, 28], Delichatsios et al. [29], Quintiere and Harkleroad [30], Brehob and Kulkarni [31], and many other researchers; additional reviews are given by Joulain [32] and Brehob et al. [33]. Given the extensive amount of available data, these correlations work well for most materials that are tested. However, as any engineering fit to experimental data, these correlations rely heavily on test-specific constants, which change with geometry and are dependent on the experimental apparatus used to determine them. In addition, such correlations do not take into account the layout of the fuel sample; for example recent experiments by Tsai and Drysdale [34] have shown that the progression of the flame front depends on the way the solid fuel is mounted on the wall. The need to study fire safety in space further justifies a return to classical theory, because every material to be used in space in a microgravity environment cannot be tested on earth. Experiments by Olson and T'ien [35] using cylindrical samples of PMMA, support the theory that low-gravity flame characteristics can be generated in normal gravity by an alternative scaling methodology based on an experimentally measurable dimensionless velocity ratio. This concept is equivalent to the B-number flammability ranking parameter proposed in this study.

This work revisits the classical solution of Emmons to understand the discrepancy between experimental results and classical theory. It is shown that the reason for overprediction by the theory is due to the improper characterization of the B-number. The previous constant B-number used in calculating flame length is in fact a variable that changes with time and space. This study develops an experimental method of calculating a B-number using the standoff distance of the flame from the surface of the fuel based on the methodology outlined by Torero et al. [20], which in turn is used to model flame spread. Since the standoff distance is defined by transport in the vicinity of the reaction, it is mostly affected by the external supply of oxidizer and fuel transport from the surface. It can therefore be linked to the fuel in a direct manner, to estimate a realistic B-number that varies with the stream wise direction due to the variable loss term $Q$. This value could be used in a fire model to model a worst-case scenario to estimate the risk associated with a particular material in an environment prone to fire hazards. A ranking system using the B-number is ideal for characterizing material flammability in space, where high oxygen concentrations (typically $30 \%$ by volume) and small confined spaces could increase fire hazard; a clear benefit is the ability to measure the B-number under earth gravity conditions, avoiding the need for expensive microgravity experiments. 
Numerical evaluation of the assumptions used in the classical boundary layer theory (Rouvreau et al. [36]) show that the boundary layer approximation breaks down and separation of the flow occurs when the ration

of $\frac{v_{f}}{U_{\infty}}$ (fuel injection velocity/ free stream velocity) also called as the dimensionless volume coefficient [30] is greater than 0.16 . The current study does not apply to this regime.

\section{MATHEMATICAL FORMULATION}

The details of the mathematical analysis are presented elsewhere [37] and only the main results of the analysis will be discussed here. For an upward spreading flame in a free convective environment, the standoff distance can be represented as:

$y_{f}=\left(x^{1 / 4} / C\right) \int_{0}^{\eta_{f}}\left[\left(\frac{h}{h_{w}}-1\right)\left(\frac{T_{p}-T_{\infty}}{T_{p}}\right)+1\right] d \eta$,

where $\frac{h}{h_{w}}=\frac{B+\tau-B F}{\tau}$, and $C=\left(\frac{L g}{4 C_{P} T_{\infty} v_{w}^{2}}\right)^{1 / 4}\left(\mathrm{~cm}^{-3 / 4}\right)$. It is observed from Equation (3), that the standoff distance and the B-number are related by a relationship of the form:

$y_{f}=A_{\text {free }} x^{1 / 4}$.

$A_{\text {free }}$, is a constant that represents the integral in Equation (3) multiplied by $1 / C$. The integral takes different values based on the B-number. The subscript "free," denotes that the flow-field is driven by natural-convection. A similar relationship can also be obtained for a forced convective flow-field, where in this case $y_{f}=A_{\text {forced }} x^{1 / 2}$. Previous work has shown that the relationship between $A_{\text {free }}$ and the B-number is linear $[38,39]$.

The upward progression of the flame is determined by measuring the flame length $x_{f}$ with respect to the pyrolysis length $x_{p}$. Pagni and Shih [25] and Annamalai and Sibulkin [19], extend the similarity solution beyond the pyrolysis length to theoretically determine the flame length. $x_{f}$ depends on the excess fuel fraction $F_{e}$, which is a ratio of excess-pyrolyzate to the total pyrolyzate. Using results from Annamalai and Sibulkin [40], the flame length is given as:

$x_{f}=x_{p}\left(1-F_{e}\right)^{-\frac{4}{3}}$,

where, $F_{e}=\frac{\dot{M}_{f, e}^{\prime}}{\dot{M}_{f}^{\prime}}$ is the excess-fuel-fraction that is present beyond the pyrolysis length $x_{p}$. Pagni and Shih [25] show that $F_{e}$ is a function of the B-number. $\dot{M}_{f, e}^{\prime}$ is the excess pyrolyzate defined by Pagni and Shih [25] and $\dot{M}_{f}^{\prime}$ is the total mass released from the fuel surface.

\section{EXPERIMENTAL SET UP}

The experimental combustion set-up consists of a vertical sample of the solid fuel (PMMA) $50 \mathrm{~cm}$ in height, $1.2 \mathrm{~cm}$ in thickness, and $5 \mathrm{~cm}$ in width, mounted on an insulation board and covered with a metal plate, as illustrated in Fig. 2. The test set up is similar to the current NASA Upward Flame Propagation Test. 


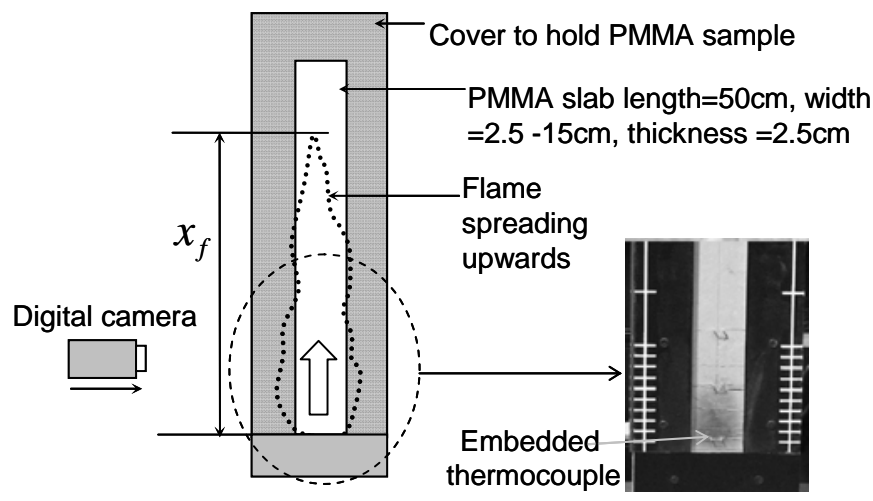

Fig. 2: Experimental set up

The metallic cover, extending $5 \mathrm{~cm}$ on each side of the sample, allows only the front surface of the fuel to ignite and burn. The sample is ignited at the bottom using a gas burner. A ruled reference on the plate provides a visual indication of the extent of flame spread at a given time. Five thermocouples are fed through holes drilled from the back of the sample and melted on to the surface, and five additional thermocouples are placed on the back of the sample between the fuel and the insulation. The thermocouples are evenly spaced to provide temperature data, indicating the progression of the pyrolysis front and an estimate of the thermal thickness of the material. A digital camera (Canon G5) is used to obtain a side view of the flame. The field of view is chosen to obtain an error on the stand-off distance of less than $5 \%$. Based on the characteristic time scales for propagation, an average of all images in a 10 second period was used to obtain an average stand-off distance and flame shape. First, each image is converted to gray levels (0-255) and then all values are averaged leading to an average image. The stand-off distance and flame length are determined by establishing a threshold gray level. The threshold value was varied as a part of a sensitivity analysis which ultimately illustrated that both stand-off distance and flame length did not vary significantly with the choice of gray level. The stand-off distance was corrected for fuel regression through measurements of the burned samples after the test. Linear functions of time and location were established for the surface regression rates and added to the stand-off distance; this correction never exceeded $10 \%$ of the total value. The results presented in this study use this corrected value of the standoff distance. Overall six replicate experiments were conducted and good agreement was found between runs.

\section{EXPERIMENTAL RESULTS AND DISCUSSION}

\section{Stand-off distance}

The stand-off distance of the upward spreading flame, is obtained from the side-view images taken by the digital camera. Figure 3 shows a plot of the stand-off distance plotted with respect to the normalized stream wise direction $\left(x / x_{p}\right)$, at 10 second time intervals for a $5 \mathrm{~cm}$ wide sample of PMMA. Figure 3 shows that with the progress of time, the stand-off distance increases. As $x_{p}$ increases, the mass burning rate increases, causing more fuel to be vaporized per unit time. This increase causes the flame to lift further up from the surface of the fuel, causing an increase in stand-off distance. 


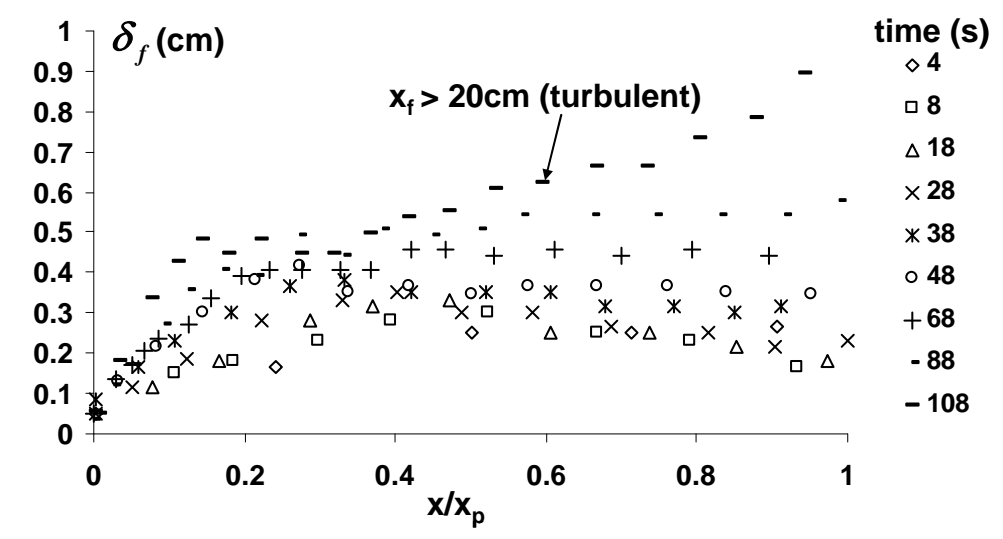

Fig. 3: Stand-off distance $\delta_{f}(\mathrm{~cm})$ as a function of normalized stream wise direction $x / x_{p}$

Using Equation (4), an experimental value of " $A_{\text {free }}$ " is obtained from Fig. 3, which allows calculation of the B-number from the standoff distance.

\section{Evolution of the B- number with time}

A plot of the B-number as a function of time is obtained from the experimental data, shown in Fig. 4. Overall, Fig. 4 illustrates that the B-number increases with time during the flame spread process. B-number data taken from $x / x_{p}=0.2$ and the trailing edge $x / x_{p}=1$ are shown, taken from the average of five experiments. For PMMA, a B-number lies in the shaded area shown in Fig. 4, with an average B-number shown by the dashed line. The average B-number value is used in predicting the experimentally observed flame length.

As shown in Fig. 4, the flame is laminar early in the propagation phase, and becomes turbulent after about $100 \mathrm{~s}$, when the flame length is greater than $20 \mathrm{~cm}$. It is observed that during the early stages of the fire, when the flame lengths are small, the B-number is higher at the leading edge than at the trailing edge. As the flame length increases, and the flame becomes turbulent, this trend reverses, and the B-number at the trailing edge increases. This behavior is attributed to the convective and radiative-loss terms in the definition of the B-number. For small flame lengths, the convective heat flux from the flame plays a dominating role. Orloff et al. [23] have found that convection is important for flames less than approximately $20 \mathrm{~cm}$ in length, and flame radiation becomes dominant for larger flames. Ahmad and Faeth [41] show that convection is approximately 80 to $90 \%$ of heat transfer to the fuel for wall fires generated by fuel soaked wicks.

Two parallel dotted lines are drawn in Fig. 4. The lower dotted line represents the maximum B-number for laminar flame propagation, $B_{R}=0.92$ for PMMA. This value is $70 \%$ lower than the B-number measured by Kanury [21] for a PMMA pool fire including radiative losses and 52\% lower than the adiabatic B-number used traditionally by Emmons [15]. The trailing edge B-number, increasing with time eventually exceeds $B_{R}$. At this point $\left[-\dot{q}_{f, r}^{\prime \prime}+\dot{q}_{s, r}^{\prime \prime}+\dot{q}_{s, c}^{\prime \prime}\right]<0$, because the flame radiation $\dot{q}_{f, r}^{\prime \prime}$ exceeds conduction and surface radiation losses. This is possible when the flame gets large and turbulent or when increasing soot concentration causes flame emission to increase. The upper dotted line represents the adiabatic B-number $\left(B_{A}\right)$. It is observed that the experimentally measured $B_{R}$, is approximately half the value of the adiabatic B-number $B_{A}$. This explains why previous works, e.g. [20, 24], overestimate the flame length by approximately a factor of two.

The B-number changes along the streamwise direction, because the loss term $Q$ is not a constant. An average B-number following a power law relationship with time is used in predicting current experimental results with a theoretical formulation developed by Annamalai and Sibulkin [19, 40]. The theory is validated with experimental results from previous works cited in literature as well. A numerical model that incorporates the changing B-number as a function of time and space depending on the energy balance at the 
fuel surface is necessary to model the complicated problem of flame spread. The simplified analysis developed by Annamalai and Sibulkin $[19,40]$ is used to show qualitatively, the dependency of flame length on a variable B-number.

To compare experimental data reported in literature [42] with current results, the following average Bnumber relationship is used:

$B_{\text {avg }}=\frac{\int_{0}^{t} 0.17 t^{0.326} d t}{t}$.

With $t=350 \mathrm{~s}$ which is the average time for each experiment in the current study, an average B-number is calculated as $B_{\text {avg }}=0.86$. This average value is used in the analysis for predicting flame length.

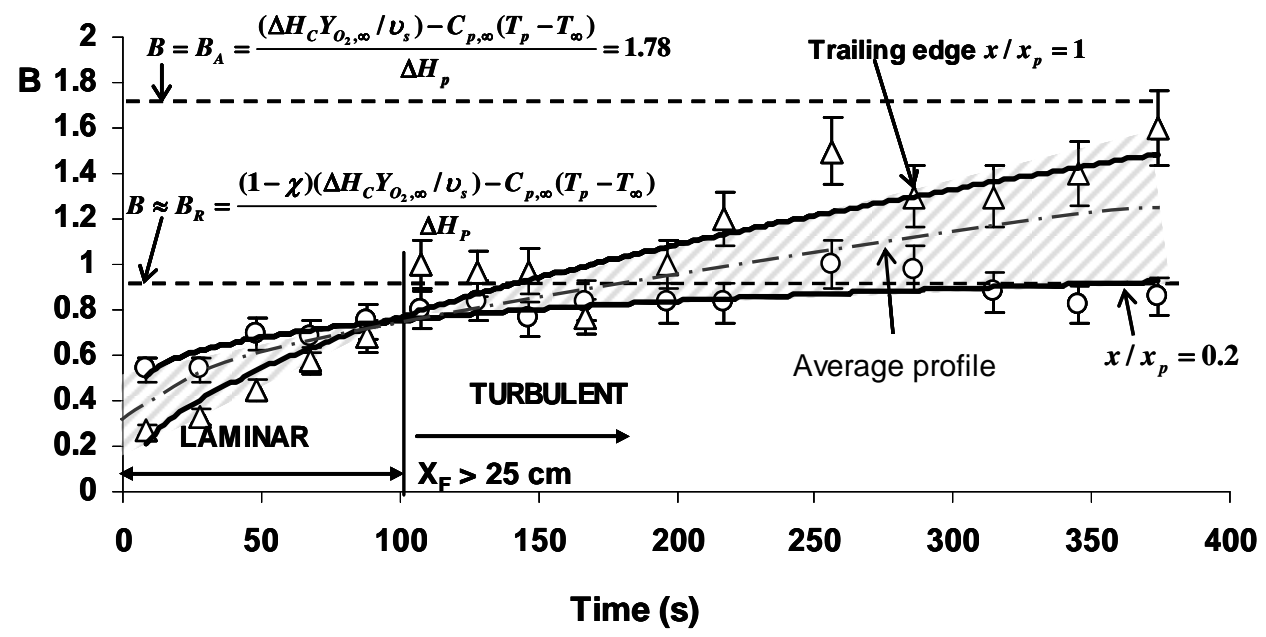

Fig. 4: Evolution of the B-number with time. The shaded area represents the range of B-number values that are possible for upward flame spread on PMMA.

When the heat flux from the flame is predominantly convective in nature, it is observed that the B-number is high at the leading edge and decreases progressively along the streamwise direction. This is because the loss term $Q$ decreases due to an increase in the burning rate along the streamwise direction. Flame length is needed to obtain flame spread rates. To obtain flame length it is necessary to determine the excess pyrolyzate, which is the mass flux of the fuel that is not burned in the boundary layer, but is burned upstream beyond the pyrolysis length. Using the theory developed by Pagni and Shih [25], the excess pyrolyzate can be determined. The excess pyrolyzate depends on the B-number; recent work published by the authors' shows that the excess pyrolyzate is also a function of the width of the fuel [43]. Assuming that all the excess pyrolyzate is burned upstream, a flame length can then be obtained. Earlier estimates of flame length led to an overprediction because the B-number used to calculate the excess pyrolyzate was overestimated. As explained in this work, the B-number obtained from the standoff distance can be successfully used to predict flame length as a function of time.

\section{Prediction of flame length as a function of time}

Assuming that all the excess pyrolyzate is burned upstream, a flame length can be obtained with respect to time using Equation 5 with the pyrolysis length as a function of time is obtained from Annamalai and Sibulkin [19]. Figure 5 shows the flame length obtained using the adiabatic $B$-number value $\left(B=B_{A}\right)$ for PMMA, which substantially overpredicts the data. In contrast, the laminar flame lengths are predicted reasonably well when a B-number obtained from the current measurements is used. The experimental flame lengths obtained in this work as well as from previous work cited in the literature [42] show good agreement with theory. 


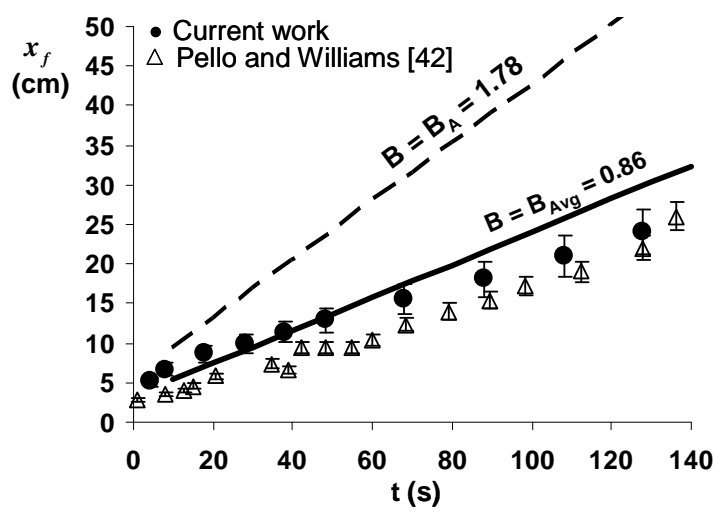

Fig. 5: Flame length as a function of time. The dark solid line represents the theoretical curve obtained using the average $\mathrm{B}$-number relationship of $\mathrm{B}_{\mathrm{avg}}=0.86$. The dashed line represents the analytical solution for flame length as a function of time using an adiabatic B-number.

\section{Implications to Microgravity}

The variation of the flame length normalized by the pyrolysis length as a function of the free stream velocity, $U_{\infty}$ for four different values of $Y_{\mathrm{O}_{2}}$ is presented in Fig. 6 . This data is obtained by Torero et al. [20] during parabolic flights to benefit from the extended microgravity. Figure 6 shows a linear increase of the flame length with $U_{\infty}$. Below $150 \mathrm{~mm} / \mathrm{s}$ the ratio $x_{f} / x_{p}$ becomes smaller than one. In this region an increase in oxygen concentration results in an increase in the flame length. For $U_{\infty}>150 \mathrm{~mm} / \mathrm{s}$ the flame becomes longer than the pyrolysis length $\left(x_{f} / x_{p}>1\right)$ implying the presence of excess pyrolyzate. For $U_{\infty}>150 \mathrm{~mm} / \mathrm{s}$ an increase in the oxygen concentration results in a decrease in the flame length. The theoretical predictions for the flame length using $B_{R}$ and $B_{c}$ values for PMMA are also shown in Fig. 6. It is observed that the microgravity data falls in between the two lines representing ratios of $x_{f} / x_{p}$ for $B=B_{R}$ (upper solid line) and $B=B_{C}$ (lower solid line). A critical B-number $\left(B_{c}\right)$ is deduced by setting the excess pyrolyzate, $F_{e}=0$ in the theory developed by Pagni and Shih[25].

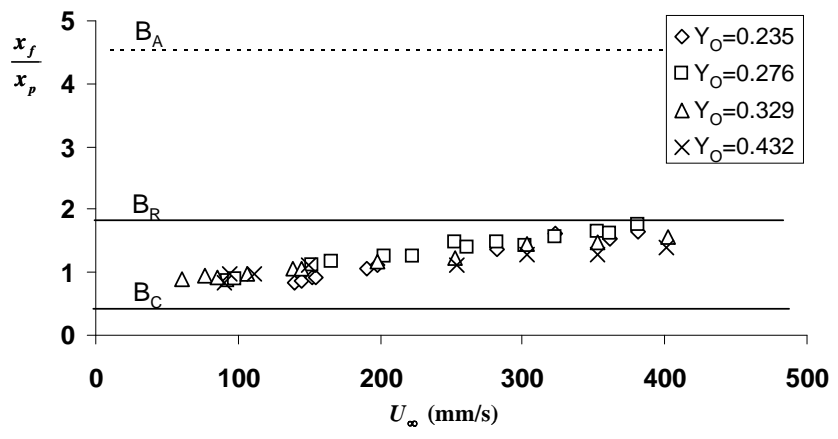

Fig. 6: Use of $B_{R}$ and $B_{C}$ to model flame spread in microgravity.

According to the current theory, $x_{f} / x_{p}$ is independent of the free-stream velocity $U_{\infty}$. This is because the present analysis assumes infinite chemistry and the flame length is defined as the place where total consumption of the excess pyrolyzate occurs. Theory can therefore not predict gas-phase extinction at the trailing edge. The experimental results show that a critical condition is attained at $U_{\infty}>150 \mathrm{~mm} / \mathrm{s}$ beyond which the excess pyrolyzate can not burn and $x_{f} / x_{p} \approx 1$. The theoretically-determined $B_{c}$ is below this 
critical limit. For $U_{\infty}<150 \mathrm{~mm} / \mathrm{s}$ an increase in the free-stream oxygen concentration will enhance the gasphase chemistry and therefore the flame length will increase, for $u_{\infty}>150 \mathrm{~mm} / \mathrm{s}$ the flame length will try to follow the tendencies established by the boundary condition at the edge of the sample, but again, extinction will occur once the flame attains the gas-phase critical condition. This explains the lack of dependency of $x_{f} / x_{p}$ on $x_{p}$, since for fixed flow conditions, $x_{p}$ will have a weak effect on the critical condition, therefore, the gas-phase will dominate over the excess-pyrolyzate. A detailed study of the trailing edge extinction is required to exactly understand the quenching regime.

\section{CONCLUSION}

In this work, a B-number is obtained from experimental measurements of the standoff distance following the methodology of Torero et al. [20], which can be used to predict burning rate, excess pyrolyzate, flame length, and flame spread rate. Experimental results show that the B-number thus obtained is not a constant, but changes as a function of space and time. Earlier experiments ignored these losses, or included them in an ad hoc way, causing overprediction of theory with experimental data. This is because the loss term, $Q$, in the definition of the B-number, was either assumed to be equal to zero [15], or a constant, depending on the radiative-emission of the flame [21]. Using the standoff distance to estimate the B-number circumvents the need to calculate the loss-term independently. The heat required to pyrolyze fuel is obtained from the gas-phase combustion reaction, and the location of the reaction front depends on the fuel burning-rate $\dot{m}_{f}^{\prime \prime}$, which depends on the solid phase, as well as the diffusion, and convection of fuel and oxygen, which occur in the gas phase. The standoff distance incorporates all these effects implicitly and therefore is linked to the fuel in a direct manner.

\section{ACKNOWLEDGEMENTS}

This work is part of the author's PhD dissertation thesis in Engineering Sciences (Mechanical Engineering) at UC San Diego. The author would like to thank his advisor Professor Steven Buckley. In addition, the author would also like to thank Professor Jose Torero for his guidance during the course of the dissertation. The author also thanks his committee members, especially Forman Williams and Kalyanasundaram Seshadri, for many helpful discussions and valuable feedback and also Professor James Quintiere at University of Maryland, and Professor Carlos Fernandez-Pello at UC Berkeley for their expert comments. The author would also like to thank Dr. Gary Ruff and Dr. Fletcher Miller of NASA for helpful insight and facilitation, and the NASA Fire Safety Program of the Bioastronautics Initiative, Grant \# NAG-32568 for support of this research.

\section{REFERENCES}

[1] NASA, "Flammability, Odor, off gassing, and Compatibility Requirements and Test Procedures for Materials in Environments that Support Combustion," NASA-NHB 8060.1, (1981).

[2] MSFC-HDBK-527-REV F, Materials Selection List for Space Hardware Systems, (1988).

[3] Friedman, R. Fire safety in the low gravity spacecraft environment. in Second International Micro-gravity Combustion Workshop, 1993, NASA Lewis Research Center.

[4] Engel, C.D., Private communications. Qualis Corp, 2005.

[5] Ohlemiller, T. J. and .Villa, K. M., (1991) Material flammability test assessment for space station freedom, in National Institute of Standards and Technology, NISTIR-4591.

[6] Torero, J.L., Bahr, N.J. and Carman, E.J. Assessment of material flammability for micro-gravity environments. in 48th International Astronautical Federation congress. 1997. Turin, Italy.

[7] Coutin, M., Rangwala, A.S., Buckley, S.G. and L., T.J. Material properties governing co-current flame spread in microgravity: The effect of air entrainment. in 7th NASA microgravity combustion workshop. 2003, June 3-6. Cleveland, Ohio.

[8] Rangwala, A.S., Torero, J.L. and Buckley, S.G. Towards determination of the b number for cocurrent flame spread using the fire dynamic simulator (fds) code: Comparison between model and 
experiment. in Fall Technical Meeting of the Western States Section of the Combustion Institute. 2003. University of California, Los Angeles.

[9] Rangwala, A.S., Buckley, S.G. and Torero, J.L. Modeling and analysis of the upward burning of pmma. in 43 rd AIAA Aerospace Sciences Meeting and Exhibit, 2005. 2005. AIAA, Reno, NV.

[10] Ruff, G., Rangwala, A.S., Buckley, S.G. and Torero, J.L., Understanding material property impacts on co-current flame spread: Improving understanding crucial for fire safety, NASA tech rep., 2004.

[11] Grayson, G., Sacksteder, K.R., Ferkul, P.V. and T'ien, J.S., (1994) Flame spreading over a thin solid in low-speed concurrent flow-drop tower experimental results and comparison with theory, Microgravity Science and Technology, VII/2: 187-195.

[12] Ferkul, P.V. and T'ien, J.S., (1994) A model of low-speed concurrent flow flame spread over a thin fuel, Comb. Sci. and Tech., 99: 345 -370. http://dx.doi.org/10.1080/00102209408935440

[13] Kashiwagi, T., Mell, W.E., McGrattan, K., Baum, H.R., Olson, S.L., Fujita, O., Kikuchi, M. and Ito, K. Ignition, transition, flame spread in multidimensional configurations in microgravity. in Fourth International Micro-gravity Combustion Workshop, 1997, NASA Lewis Research Center.

[14] T'ien, J.S., (1990) The possibility of a reversal of material flammability ranking from normal gravity to microgravity, Combust. Flame, 80: 353-357.

[15] Emmons, H., (1956) The film combustion of liquid fuel, Z. angew. Math. Mech, 36: 60-71.

[16] Lees, L., (1956) Laminar heat transfer over blunt nosed bodies at hypersonic flight speeds, Jet Propulsion, 26: 259-269.

[17] Spalding, D.B., (1950) Combustion of liquid fuel in gas stream. Fuel, 1950. 29: p. 2-7.

[18] Vietoris, T., Joulain, P. and Torero, J.L., Experimental observations on the geometry and stability of a laminar diffusion flame in microgravity, International Symposium on Fire Safety Science, 1999. 6: p. 373-386.

[19] Annamalai, K. and Sibulkin, M., (1979) Flame spread over combustible surfaces for laminar flow systems. Part 1: Excess fuel and heat flux, Combust. Sci. Tech., 19: 167-183. http://dx.doi.org/10.1080/00102207908946878

[20] Torero, J.L., Vietoris, T., Legros, G. and Joulain, P., (2002) Estimation of a total mass transfer number from stand-off distance of a spreading flame Combust. Sci. Tech., 174(11-12): 187-203.

[21] Kanury, A.M., Modeling of pool fires with a variety of polymers. Proc. Combust. Instit., 1974. 15: p. 193-201.

[22] Holve, D.J. and Sawyer, R.F., Diffusion controlled combustion of polymers. Proc. Combust. Instit. 15: p. 351-361.

[23] Orloff, L., de Ris, J. and Markstein, G.H., Upward turbulent fire spread and burning of fuel surface. Proc. Combust. Instit., 1974. 15: p. 183-192.

[24] Fernandez-Pello, A.C., A theoretical model for the upward laminar spread of flames over vertical fuel surfaces. Combust. Flame, 1978. 31: p. 135-148. http://dx.doi.org/10.1016/0010$\underline{2180(78) 90124-4}$

[25] Pagni, P.J. and Shih, T.M., Excess pyrolyzate. Proc. Combust. Instit., 1978. 16: p. 1329-1343.

[26] Quintiere, J.G., (1981) A simplified theory for generalizing results from a radiant panel rate of flame spread apparatus, Fire and Materials, 5(2): 52-60. http://dx.doi.org/10.1002/fam.810050204

[27] Saito, K., Williams, F.A., Wichman, I.S. and Quintiere, J.G. (1989), Upward turbulent flame spread on wood under external radiation, Journal of Heat Transfer, 111: 438-445. 
[28] Saito, K., Quintiere, J.G. and Williams, F.A., Upward turbulent flame spread, Fire Safety Science - Proceedings of the $1^{\text {st }}$ International Symposium, International Association for Fire Safety Science 1986: p. 75.

[29] Delichatsios, M.A., Delichatsios, M., Chen, Y. and Hasemi, Y., (1995) Similarity solutions and applications to turbulent upward flame spread on non charring materials, Combust. Flame, 102: 357-370. http://dx.doi.org/10.1016/0010-2180(94)00285-Z

[30] Quintiere, J.G. and Harkleroad, M.F., New concepts for measuring flame spread properties. National Bureau of Standards, 1984. NBSIR-84-2493.

[31] Brehob, E.G. and Kulkarni, A.K., (1998) Experimental measurements of upward flame spread on a vertical wall with external radiation, Fire Safety Journal, 31: 181-200. http://dx.doi.org/10.1016/S0379-7112(98)00012-5

[32] Joulian, P., (1996) Convective and radiative transport in pool and wall fires: 20 years of research in Poitiers, Fire Safety Journal, 26: p. 99-149. http://dx.doi.org/10.1016/0379-7112(96)00004-5

[33] Brehob, E.G., Kim, C.I. and Kulkarni, A.K., (2001) Numerical model of upward flame spread on practical wall materials, Fire Safety Journal, 36(3): p. 225-240. http://dx.doi.org/10.1016/S0379$\underline{7112(00) 00054-0}$

[34] Tsai, K.G. and Drysdale, D.D., (2002) Flame height correlation and upward flame spread modeling. Fire and Materials, 26: 279-287. http://dx.doi.org/10.1002/fam.809

[35] Olson, S.L. and T'Ien, J.S., (2000) Buoyant low-stretch diffusion flames beneath cylindrical pmma samples. Combust. Flame, 121(3): p. 439-452. http://dx.doi.org/10.1016/S0010-2180(99)00161-3

[36] Rouvreau, S., Torero, J.L. and Joulain, P., (2005) Numerical evaluation of boundary layer assumptions for laminar diffusion flames in microgravity, Combust. Theory and Modelling, 9(1): 137-158. http://dx.doi.org/10.1080/13647830500098381

[37] Rangwala, A.S., Flame spread analysis using a variable B-number, $\mathrm{PhD}$ dissertation in Mechanical and Aerospace Eng. 2006, University of California, San Diego.

[38] Rangwala, A.S, Buckley, S.G., Dembsey, N.A. and Torero, J.L, The relationship between gasphase standoff distance and the solid-phase, Fire and Explosion Hazards, 2007. Edinburgh, UK.

[39] Rangwala, A.S., Buckley, S.G. and Torero, J.L., (2008) Analysis of the constant b-number assumption while modeling flame spread, Comb. and Flame, 152(3): 401-414.

http://dx.doi.org/10.1016/j.combustflame.2007.09.010

[40] Annamalai, K. and Sibulkin, M., (1979) Flame spread over combustible surfaces for laminar flow systems. Part 2: Flame heights and fire spread rates. Combust. Sci. Tech., 19: 185-193. http://dx.doi.org/10.1080/00102207908946879

[41] Ahmad, T. and Faeth, G.M., Turbulent wall fires. Proc. Combust. Instit., 1979. 17: p. 1149 -1160.

[42] Fernandez Pello, A.C. and Williams, F.A. (1977), A theory of laminar flame spread over flat surfaces of solid combustibles. Combust. Flame, 28: p. 251-277. http://dx.doi.org/10.1016/0010$\underline{2180(77) 90032-3}$

[43] Rangwala, A.S., Buckley, S.G. and Torero, J.L., Upward flame spread on a vertically-oriented fuel surface: The effect of finite width. Proc. Combust. Instit., 2007. 31(2): p. 2607-2615. http://dx.doi.org/10.1016/j.proci.2006.07.235 